\title{
STRATEGI KESANTUNAN TINDAK TUTUR POSITIF DAN NEGATIF OLEH KARAKTER DI FILM "LET IT SNOW" (2019)
}

\author{
${ }^{1}$ Anisah Nur Mawaddah*, ${ }^{2}$ Nurul Fitriani \\ Program Studi Bahasa dan Kebudayaan Inggris, Universitas Darma Persada \\ E-mail: hello.anisanur@gmail.com*
}

\begin{abstract}
Communication was an activity that usually occurs in the social context. People used communication to engaged each other, with a particular purpose, such as exchanging information, negotiating things, and so on. Basically, when doing communication, we should pay attention to the language politeness, in which it can show our courtesy when talking to each other. Therefore, language politeness was needed in our casual conversation. The purpose of this study was to provide an understanding of two main politeness strategies; the positive and negative politeness which are used by the characters in "Let It Snow" movie. This study used qualitative approach, and content analysis method to conducted the research. The result of the study showed that the characters in "Let It Snow" movie use positive politeness more frequently than the negative one. They used positive politeness strategy to minimize the distance between each other (speaker and listener), while negative politeness is used as a form of respecting to each other.
\end{abstract}

Keywords: politeness strategies; positive politeness; negative politeness; movie characters

\begin{abstract}
ABSTRAK
Komunikasi merupakan suatu kegiatan yang biasanya terjadi dalam suatu konteks sosial. Orang melakukan komunikasi guna berinteraksi dengan tujuan tertentu, misalnya bertukar informasi, melakukan negosiasi, dan lain sebagainya. Pada dasarnya, ketika berkomunikasi, kita haruslah memperhatikan kesantunan dalam berbahasa sebagai bentuk kesopanan kepada lawan bicara kita. Oleh karena itu, dalam melakukan percakapan sehari-hari, kesantunan berbahasa pun dibutuhkan. Tujuan dari studi ini adalah untuk memberikan pemahaman terkait dua strategi kesantunan tindak tutur, yakni kesantunan positif dan kesantunan negatif yang digunakan oleh karakter di film "Let It Snow". Studi ini menggunakan pendekatan penelitian kualitatif, dan metode analisis isi. Hasil studi menunjukkan bahwa karakter di film "Let It Snow" lebih sering menggunakan kesantunan tindak tutur positif daripada kesantunan negatif. Kesantunan tindak tutur positif digunakan untuk meminimalisir jarak antar tokoh film ketika berkomunikasi, sedangkan kesantunan tindak tutur negatif digunakan sebagai bentuk rasa hormat atau tindak kesopanan kepada lawan bicara.
\end{abstract}

Kata kunci: strategi kesantunan; kesantunan positif; kesantunan negatif; karakter film

\section{PENDAHULUAN}

Bahasa merupakan alat komunikasi yang paling esensial bagi seluruh manusia di muka bumi. Kehadiran bahasa sungguh membawa kemudahan dalam melakukan aktivitas sehari-hari kita, terutama dalam berkomunikasi satu sama lain. Tidak dapat dibayangkan bagaimana manusia dapat bertukar informasi satu sama lain, jika bahasa itu tidak ada. Ketika kita berkomunikasi menggunakan bahasa, tentu

Cara mengutip: Mawaddah, A.N. \& Fitriani, N. (2021). Strategi Kesantunan Tindak Tutur Positif dan Negatif oleh Karakter di Film "Let it Snow" (2019). Inteligensi: Jurnal Ilmu Pendidikan, 4(1), 1-8 
ada hal penting yang harus diperhatikan agar komunikasi yang dilakukan dapat berjalan lancar, yaitu pemahaman kita terkait apa yang disampaikan oleh lawan bicara. Jika kita tidak paham dengan apa yang disampaikan oleh lawan bicara kita, maka sungguh komunikasi pun bisa terhambat. Peran konteks juga penting ketika kita berkomunikasi satu sama lain. Apabila kita tidak paham konteks ketika kita berinteraksi tersebut, maka bisa saja timbul kesalahpahaman satu sama lain. Dalam ilmu Pragmatik, dapat berinteraksi menggunakan bahasa saja tidak cukup, kita haruslah mampu mempraktikkan kesantunan dalam berbahasa agar hubungan antara pembicara dan pendengar dapat terpelihara dengan baik. Oleh karena itu, kesantunan tindak tutur saat berkomunikasi perlu diterapkan baik oleh penutur maupun pendengar untuk menyelamatkan citra diri seseorang.

Fenomena kesantunan tindak tutur pada faktanya tidak hanya terjadi di dunia nyata, melainkan juga tercermin di berbagai karya sastra, dimana tokoh atau karakter dalam karya tersebut bertutur kata satu sama lain secara santun, bergantung kepada konteks narasi atau adegan dalam karya sastra tersebut. Oleh sebab itu, penelitian ini hadir guna memberikan gambaran terkait penggunaan kesantunan tindak tutur oleh tokoh atau karakter di salah satu jenis karya sastra, yaitu film. Film yang digunakan sebagai objek penelitian berjudul "Let it Snow", dipilih karena peneliti melihat bahwa si penulis naskah menggunakan film sebagai media menyampaikan ide atau tuturan dari tokoh yang diciptakannya, dan baik secara sadar maupun tidak sadar, tuturan para tokoh tersebut dapat diklasifikasikan ke dalam bentuk kesantunan tindak tutur.
Verhaar (1996:14) mendefinisikan pragmatik sebagai cabang linguistik yang membahas tentang struktur bahasa sebagai alat komunikasi antara penutur dan pendengar, dan sebagai acuan tanda bahasa pada hal-hal "ekstra lingual" yang diucapkan. Makna ekstra lingual termasuk unsur-unsur yang berada di luar bahasa, seperti hal-hal yang berkaitan dengan makna, informasi, konteks, dan ujaran. Yule (1996:3) mendefinisikan pragmatik sebagai studi tentang makna kontekstual, yang harus melibatkan interpretasi tentang apa yang orang maksudkan dalam konteks tertentu, dan bagaimana konteks mempengaruhi apa yang dikatakan oleh pembicara. Sementara itu, Leech (1999:6) mengatakan pragmatik adalah studi tentang makna dalam kaitannya dengan situasi tutur. Dengan kata lain, penutur harus memperhatikan kelancaran dalam berkomunikasi, penutur dan pendengar harus memahami tata cara berbahasa yang baik. Pada umumnya, seseorang berbicara menggunakan konteks kedekatan dan hubungan jarak antara pembicara dan pendengar. Lakoff (1973) menjelaskan bahwa suatu tuturan dapat dikatakan santun jika pembicara tidak terdengar arogan, memberikan kebebasan kepada pendengar, dan membuat pendengar merasa senang.

Markhamah seperti yang dikutip oleh Saputry (2016:150) mengemukakan bahwa kesantunan dalam berbahasa adalah cara seorang penutur untuk membuat mitra tuturnya tidak merasa tertekan, tersudut, maupun tersinggung, ketika mereka berkomunikasi. Brown dan Levinson (1987) menjelaskan bahwa kesantunan berbahasa adalah cara menyampaikan tuturan sesopan mungkin yang dalam hal ini diperlukan untuk meminimalisir 
konflik dengan orang lain. Leech (1999) juga menjelaskan kesantunan adalah bentuk perilaku komunikatif yang sering ditemukan dalam interaksi manusia. Ismari (1995:35) menyatakan bahwa suatu interaksi sosial dikatakan sukses apabila penutur dan mitra tutur dapat saling memahami status satu sama lain. Strategi kesantunan tindak tutur pun hadir sebagai cara bagi penutur dan mitra tutur untuk berinteraksi tanpa "mempermalukan" diri satu sama lain.

Strategi kesantunan tindak tutur postitif digunakan untuk meminimalisir jarak antara pembicara dan pendengar, yang biasanya berisi ungkapan rasa peduli satu sama lain, pujian, dan keramahtamahan. Bentuk kesantunan ini biasanya dilakukan pada ruang lingkup orang dekat, misalnya keluarga, teman, atau orang lain yang kita kenal dengan baik. Brown dan Levinson (1987) mengungkapkan bahwa kesantunan tindak tutur positif bertujuan untuk memberikan citra diri positif pendengar atau mitra tutur. Sedangkan kesantunan tindak tutur negatif biasanya digunakan ketika penutur ingin menyampaikan sesuatu namun di waktu yang bersamaan, ia tidak ingin menyinggung mitra tuturnya tersebut (Cahyaningsih, 2013; Deng, 2014) Kesantunan jenis ini digunakan sebagai bentuk tindak kesopanan kepada lawan bicara.

\section{METODE PENELITIAN}

Pendekatan penelitian yang digunakan adalah pendekatan kualitatif dengan metode analisisis isi untuk melakukan analisis mendalam terkait temuan data dari film "Let It Snow". Saryono (2010) mengungkapkan bahwa penelitian kualitatif bertujuan untuk menyelidiki, menemukan, serta mendeskripsikan, dan menjelaskan kualitas atau ciri-ciri pengaruh sosial yang tidak dapat dijelaskan, diukur, atau digambarkan melalui pendekatan kuantitatif. Sementara itu, analisis isi adalah teknik untuk menganalisis makna komunikasi yang dilakukan oleh manusia. Fraenkel dan Wallen (2007:83) mendefinisikan analisis isi sebagai teknik yang memungkinkan peneliti mempelajari perilaku manusia secara tidak langsung, melalui komunikasi analisisnya.

Sumber data penelitian ini adalah transkrip film "Let It Snow" yang dirilis pada tahun 2019 dan ditulis oleh Cannon dan Strouse. Pengambilan data dilakukan menggunakan teknik purposive sampling dimana peneliti memilih dan menggunakan data yang sesuai dengan tujuan penelitian. Guna mengecek keabsahan data, peneliti melakukan triangulasi, sehingga data yang digunakan pada penelitian ini dapat dipertanggungjawabkan. Teknik analisis data yang digunakan dalam penelitian ini, antara lain: 1) peneliti mengumpulkan data yang sesuai dengan tujuan penelitian, yakni membahas penggunaan kesantunan tindak tutur dalam film; 2) peneliti mengklasifikasikan temuan data berdasarkan jenis kesantunan tindak tutur, yaitu positif dan negatif; 3) peneliti melakukan interpretasi data; dan 4) melakukan penarikan kesimpulan.

\section{HASIL DAN PEMBAHASAN}

Berikut adalah beberapa hasil temuan kesantunan tindak tutur positif dan negatif yang dilakukan oleh karakter di film "Let It Snow" beserta dengan pembahasannya: 
Datum 1: Strategi Kesantunan Tindak Tutur Positif

Angie : "It is Movie Marathon Day, so, Queso Deluxe!"

Tobin : "Queso Deluxe!"

(Cannon and Strouse, 2019, p.2)

Dari dialog di atas, tampak karakter Angie menyampaikan ujaran yang menunjukkan kedekatannya dengan tokoh Tobin. Kedekatan tersebut ditunjukkan dengan adanya ajakan untuk menyantap Queso Deluxe bersama-sama karena mereka seharian akan menonton film bersama. Karakter Tobin pun merespon ajakan Angie, dengan menyampaikan hal yang sama yang menandakan bahwa ia menerima ajakan Angie untuk menyantap Queso Deluxe bersama-sama. Oleh karena itu, datum satu di atas dapat dikategorikan ke dalam bentuk kesantunan tindak tutur positif. Pramujiono (2011:49) mengutip Brown dan Levinson, mengatakan bahwa salah satu alasan kesantunan tindak tutur positif digunakan oleh penutur adalah untuk memberikan perhatian terkait kesukaan, keinginan, dan/atau kebutuhan. Sehingga, apabila dikaitkan pada datum pertama di atas, balasan tuturan yang disampaikan Tobin merupakan bentuk persetujuan darinya untuk memenuhi keinginan dari Angie dengan melakukan pengulangan tuturan.

Datum 2: Strategi Kesantunan Tindak Tutur Positif

JP Lapierre : "So, you guys play broomball?"

Angie : "Love broomball!"

JP Lapierre : "Alright, sweet! You are on my team. Come on, man!"

(Cannon and Strouse, 2019, p.12)
Pada datum dua di atas, tampak terjadi komunikasi antara tokoh Lapierre dan Angie. Lapierre bertanya kepada Angie apakah dia bermain broomball atau tidak, yang kemudian direspon secara antusias oleh Angie. Balasan ujaran dari Angie menunjukkan bahwa dia tidak hanya bisa bermain broomball, namun mencintai permainan tersebut. Setelah itu, Lapierre pun merespon dengan langsung mengajak Angie bergabung ke dalam timnya. Percakapan antara Lapierre dan Angie di atas dikategorikan ke dalam kesantunan tindak tutur positif karena tampak jelas bahwa Angie mengungkapkan kecintaannya pada permainan broomball yang kemudian membuat Lapierre senang akan ujaran tersebut. Kusumaswarih (2018:146) menjelaskan bahwa kesantunan positif biasanya digunakan untuk menghindari ancaman muka positif, oleh sebab itu, dalam berkomunikasi, penutur biasanya berusaha melibatkan dirinya bersama dengan mitra tutur dalam suatu kegiatan tertentu.

\section{Datum 3: Strategi Kesantunan Tindak Tutur Positif}

Addie : "You are an incredible friend. You make me laugh when I am freaked out."

(Cannon and Strouse, 2019, p.41)

Ujaran yang disampaikan oleh karakter Addie pada datum tiga di atas menunjukkan bahwa ia menyampaikan suatu sanjungan atau pujian kepada lawan bicaranya, yang dalam konteks ini adalah seorang teman. Addie yang merasa senang memiliki teman yang baik kepadanya, akhirnya mengekspresikan kebahagiaan dia tersebut dengan menyampaikan pujian 
tersebut. Tentu saja, sudah jelas bahwa ujaran di atas termasuk ke dalam kategori kesantunan tindak tutur positif karena karakter Addie tak sungkan menunjukkan apresiasinya akan citra diri positif dari lawan bicaranya, meskipun terkesan terlalu berlebihan dalam sampaian sanjungan tersebut.

\section{Datum 4: Strategi Kesantunan Tindak} Tutur Negatif

Conductor: "Ladies and gentlemen, we apologize for the delay. We are doing everything we can to get you moving as soon as possible."

(Cannon and Strouse, 2019, p.7)

Menurut Kusumaswarih (2018), kesantunan tindak tutur negatif dilakukan dengan cara penutur mengakui, menghormati, dan memberikan kebebasan bertindak kepada lawan tuturnya. Ujaran pada datum empat di atas menunjukkan adanya penyampaian informasi dari seorang konduktor kereta kepada para penumpang terkait keterlambatan yang disebabkan adanya timbunan salju yang menutupi lajur kereta.

$$
\text { Ujaran konduktor tersebut }
$$

dimasukkan ke dalam kesantunan tindak tutur negatif karena dalam ujaran tersebut, dapat kita tafsirkan bahwa sang konduktor merasa tidak enak kepada para penumpang terkait keterlambatan yang terjadi. Oleh karena itu, ia pun menyampaikan permintaan maaf, dan berusaha meyakinkan penumpang bahwa petugas sedang berusaha mengatasi gangguan yang terjadi secepat mungkin (Autio, 2016). Adanya perbedaan status sosial antara petugas dan penumpang pun menyebabkan sang konduktor menyampaikan tuturan dengan pilihan kata yang sopan agar tidak membuat mitra tuturnya menjadi tersinggung.

\section{Datum 5: Strategi Kesantunan Tindak Tutur Negatif}

Dorrie : "Julie, could you actually save my life and get a mop from the closet? It is by the office."

Julie : "Uh, yeah, sure, OK."

(Cannon and Strouse, 2019, p.46)

Saputry (2016) mengungkapkan bahwa salah satu strategi yang digunakan oleh penutur ketika melakukan kesantunan tindak tutur negatif adalah dengan meminimalkan paksaan kepada lawan tuturnya. Hal itu dilakukan agar komunikasi antara penutur dan mitra tutur dapat berjalan lancar, menyenangkan, dan tidak menyinggung satu sama lain. Pada dialog di atas, karakter Dorrie menyampaikan suatu tuturan dengan maksud ingin meminta bantuan lawan tuturnya, yang dalam konteks ini adalah karakter Julie. Dalam menyampaikan maksud tuturannya, Dorrie menggunakan strategi kesantunan negatif agar pesan yang ia sampaikan tidak menimbulkan kesalahpahaman atau menyinggung perasaan Julie. Oleh karena itu, Dorrie meminta tolong dengan menggunakan pilihan kata yang sopan, seperti adanya penggunaan kata could pada datum di atas.

Dari pembahasan di atas, dapat dikatakan bahwa karakter di film "Let It Snow" menggunakan strategi kesantunan tindak tutur positif dan negatif berdasarkan konteks situasi komunikasi yang sedang terjadi. Seperti yang dijelaskan pada bagian sebelumnya, kesantunan tindak tutur hadir untuk menciptakan suasana komunikasi yang kondusif, serta meminimalisir adanya konflik yang 
mungkin saja timbul antara penutur dan mitra tutur ketika sedang berinteraksi tersebut.

\section{SIMPULAN}

Berdasarkan temuan hasil dan pembahasan, dapat dikatakan bahwa tokoh atau karakter dalam film "Let it Snow" menggunakan kesantunan tindak tutur positif kepada lawan bicaranya karena ada faktor hubungan kedekatan, misalnya pertemanan. Oleh karena itu, ketika berujar, ia pun tidak ragu untuk menyampaikan ajakan atau bahkan pujian yang bisa saja terkesan berlebihan. Sedangkan kesantunan tindak tutur negatif pada dasarnya digunakan untuk menunjukkan kesopanan sang penutur kepada lawan tuturnya, sehingga tidak jarang, sang penutur tampak seperti merendahkan dirinya sendiri karena ia tidak ingin si mitra tutur menjadi tersinggung atas ujaran yang ia sampaikan. Penutur tidak ingin menciptakan citra diri negatif di hadapan mitra tuturnya, oleh sebab itu, kesantunan tindak tutur negatif pun digunakan dalam interaksi tersebut.

Karakter di film "Let It Snow" pun ternyata lebih sering menggunakan kesantunan tindak tutur positif daripada kesantunan tindak tutur negatif. Hal itu dikarenakan di dalam film ini, kebanyakan karakter memiliki hubungan kekerabatan yang dekat antar satu sama lain, khususnya pada konteks pertemanan. Oleh karena itu, penggunaan kesantunan tindak tutur positif pun lebih sering ditemukan. Sedangkan frekuensi penggunaan kesantunan tindak tutur negatif tidak begitu sering dikarenakan konteks situasi adegan di film tersebut tidak banyak menunjukkan adanya kebutuhan penutur menggunakan strategi ini ketika berkomunikasi dengan lawan tuturnya.

\section{DAFTAR PUSTAKA}

Autio, O. (2016). Traditional craft or technology education: Development of students' technical abilities in finnish comprehensive school. International Journal of Research in Education and Science, 2(1), 75-84. https://doi.org/10.21890/ijres.05918

Brown, P., \& Levinson, S. (1987). Politeness: Some Universals in Language Usage. Cambridge: Cambridge University Wordpress.

Cahyaningsih, R. (2013). Improving Student's Writing Skill Through Genre Based Approach At TenthGrader Of Senior High School Tuban. Universitas Negeri Surabaya. Deng, L., Chen, Q., \& Zhang, Y. (2014). Developing Chinese EFL Learners' Generic Competence. A Genrebased \& Process Genre Approach New York: Springer

Fraenkel, J. R., Wallen, N.E. (2007). How to Design and Evaluate Research in Education. New York: McGrawHill.

Ismari. (1995). Tentang Percakapan. Surabaya: Airlangga University Press.

Kusumaswarih \& Kartika K. (2018). Strategi Kesantunan Berbahasa dalam Pembelajaran Bahasa Indonesia. Jurnal Belajar Bahasa, Volume 3 No. 1, September 2018, halaman 141-149.

Lakoff, Robin. (1973). The Logic of Politeness, or Minding Your P's and $Q$ 's. Chicago: Chicago Linguistics Society.

Leech, Geoffrey. (1999). Principles of Pragmatics. London: Longman. 
Pramujiono, A. (2011). Representasi Kesantunan Positif-Negatif Brown dan Levinson dalam Wacana Dialog di Televisi. Dipresentasikan dalam Kongres Internasional Masyarakat Linguistik Indonesia, 9-12 Oktober 2011, di Universitas Pendidikan Indonesia.

Saputry, D. (2016). Strategi Kesantunan Positif dan Negatif dalam Bentuk Tuturan Direktif di Lingkungan STKIP Muhammadiyah Pringsewu Lampung. Jurnal Pesona, Volume 2
No. 1, Januari 2016, halaman 149160.

Saryono. (2010). Metode Penelitian Kualitatif. Bandung: PT. Alfabeta.

Subslikescript. (2021). Let It Snow (2019) Full Transcript. https://subslikescript.com/movie/Let _It_Snow-1950235. Diakses pada 1 Juni, 2021.

Verhaar, J.W.M (1996). Asas-Asas Linguistik Umum. Yogyakarta: Gadjah Mada University. 
Inteligensi : Jurnal Ilmu Pendidikan Vol. 4, No.1, 2021. Hal 1-8 